\section{Purification of Ig-Fusion Proteins from Medium Containing Ig}

BioTechniques 25:382-385 (September 1998)

Fusion proteins are extremely useful for a wide range of experimental and clinical applications. In contrast to bacterial expression systems that have been used for cytoplasmic regions of proteins, many mammalian cell surface and secreted proteins have important features such as posttranslational modifications (e.g., glycosylation) that require expression in eukaryotic systems. Fusion proteins between the Fc region of the immunoglobulin ( $\mathrm{Ig}$ ) protein and extracellular regions of proteins have been used successfully to express functional domains for many receptors and extracellular proteins. Ig fusion proteins have been expressed by transient or stable transfection in a variety of mammalian-expression systems and in the baculovirus system (1). Similar to antibodies, the fusion proteins can be detected with reagents such as protein A that bind to the Fc region (4). However, many expression systems require the use of serum for cell growth, and the presence of large amounts of Ig in serum can make it difficult or impractical to identify and purify Fc fusion proteins by standard procedure. This may be particularly critical for Ig-fusion proteins that are expressed at relatively low levels $(<1 \mu \mathrm{g} / \mathrm{mL})$ and must be concentrated for use in various applications such as binding studies.

We have devised a general method for purification of Ig-fusion proteins from cells grown in bovine serum. The method is based on existing methods for purification of rabbit Ig from serum, and the fact that the binding of any Fc-fusion protein to ion-exchange resins differs from that of the intact immunoglobulin protein. We found that, like rabbit Ig, bovine Ig does not bind to DE-52 columns (Whatman, Clifton, NJ, USA) equilibrated in $17.5 \mathrm{mM} \mathrm{NaH}_{2} \mathrm{PO}_{4},(\mathrm{pH}$ 6.3 ), which is one of the standard conditions for purification of Ig from serum $(2,4)$. Using these conditions, all seven Ig-fusion proteins that we have tested so far (Table 1) bind to this resin and can

Table 1. Ig-Fusion Proteins with Various Combinations of Domains that Have Been Purified

\begin{tabular}{|c|c|c|c|}
\hline Ig Fusion Protein & Species & Extracellular Domains & Reference \\
\hline Contactin & Human & $6 \mathrm{lg}, 4 \mathrm{Fnlll}$ & $(7)$ \\
\hline RPTP $\beta(\beta C F S)$ & Human & $\begin{array}{l}\text { Carbonic anhydrase, } \\
\text { FnIII, S domain }\end{array}$ & (10) \\
\hline $\mathrm{RPTP} \beta(\beta \mathrm{CF})$ & Human & $\begin{array}{l}\text { Carbonic anhydrase, } \\
\text { Fnlll }\end{array}$ & (7) \\
\hline RPTP $\beta(\beta F S)$ & Human & Fnlll, S domain & (10) \\
\hline L1 & Mouse & $6 \mathrm{lg}, 5 \mathrm{FnIII}$ & (9) \\
\hline $\mathrm{Nr}-\mathrm{CAM}$ & Mouse & $3 \lg$ & $\left({ }^{*} a\right)$ \\
\hline $\mathrm{Ng}-\mathrm{CAM}$ & Chick & $6 \lg$ & $\left({ }^{* a}\right)$ \\
\hline
\end{tabular}

subsequently be eluted at elevated concentrations of salt $(0.1-0.15 \mathrm{M})$. This is the key step for separating Ig from the Ig-fusion proteins that are secreted into the culture supernatant. In a subsequent step, the Ig-fusion protein is purified using protein $\mathrm{A}$, which removes remaining proteins, most notably albumin, and yields a highly concentrated and purified protein.

The first step in the purification process is ammonium-sulfate precipitation to collect the protein fraction. All chimeric proteins tested were precipitated completely with ammonium sulfate at $60 \%$ saturation. The precipitates are collected by centrifugation and resuspended in Buffer A (17.5 mM $\mathrm{NaH}_{2} \mathrm{PO}_{4}, \mathrm{pH} 6.3$ ); the precipitate from $1 \mathrm{~L}$ of culture supernatant is typically resuspended in $40 \mathrm{~mL}$ of Buffer $\mathrm{A}$. The resuspended precipitate is dialyzed against Buffer $\mathrm{A}$ with at least three buffer changes to remove the ammonium sulfate. Insoluble material is removed by centrifugation, and the supernatant is loaded onto a DE-52 column that is pre-equilibrated in Buffer A; $20 \mathrm{~mL}$ of swollen resin are used per liter of culture supernatant. Under these conditions, nearly all of the Ig flows through the column while the Ig-fusion proteins remain bound. The DE-52 is washed extensively with Buffer A (>10 column volumes), and then the Ig-fusion protein is eluted by increasing the salt concentration (a relatively fast flow rate can be used). Most Ig-fusion proteins will elute in Buffer A containing $0.1-0.15 \mathrm{M} \mathrm{KCl}$, but occasionally higher salt $(0.3-0.5 \mathrm{M} \mathrm{KCl})$ may be needed. The eluate is pooled and alkalized by adding $1 / 10$ vol of $1 \mathrm{M}$ HEPES, $\mathrm{pH} 8.0$, to facilitate binding to Protein A-Sepharose ${ }^{\circledR}$ (Zymed Laboratories, San Francisco, CA, USA). Given the high capacity of Protein ASepharose for binding the Fc region of $\mathrm{Ig}$ (ca. $20 \mathrm{mg}$ rabbit $\mathrm{IgG} / \mathrm{mL}$ of resin), a 2-mL column is sufficient for the final purification of several $\mathrm{mg}$ of Ig-fusion protein. The beads are washed with phosphate-buffered saline (PBS) containing $0.1 \%$ Triton ${ }^{\circledR} \mathrm{X}-100$ and then with several column volumes of PBS alone to remove the detergent. Elution from Protein A-Sepharose is achieved with $100 \mathrm{mM}$ glycine, $\mathrm{pH} 2.8$, and the eluate is neutralized with $1 / 15 \mathrm{vol}$ of 1 M HEPES, pH 8.0. We have avoided the use of Tris buffer because it is toxic for some cells such as neurons. The purified protein is dialyzed into an appropriate buffer, e.g., PBS. All procedures are preformed at $4^{\circ} \mathrm{C}$. Final concentrations of protein are typically several hundred $\mu \mathrm{g} / \mathrm{mL}$, and yields as high as 1 $\mathrm{mg} / \mathrm{mL}$ have been obtained.

This procedure was particularly useful for the purification of L1-Fc since it was expressed at relatively low levels (ca. $0.5 \mu \mathrm{g} / \mathrm{mL}$ ). Culture supernatants of Chinese hamster ovary (CHO) cells expressing L1-Fc (9) were purified by the method described above. Figure 1 shows analysis of the total protein by Coomassie $^{\circledR}$ Brillant Blue stain and of L1-Fc by immunoblotting. The major component in the culture medium that contained $10 \%$ fetal calf serum (FCS) was a band at approximately $68 \mathrm{kDa}$, which is probably albumin. There was a low level 
of $\mathrm{L} 1-\mathrm{Fc}$ in the conditioned medium that was enriched by precipitation with ammonium sulfate. All of the L1-Fc bound to the DE-52 column and final purification on protein $\mathrm{A}$ beads removed most of the remaining proteins, including albumin. Whereas a one-step purification on Protein A-Sepharose recovered the L1-Fc as seen by immunoblotting (Figure 1, lower panels), this fraction consisted mostly of Ig (Panel B). This is a case where the modified purification method was critical for purifying L1-Fc given the existing method of production. Maximal yield for L1-Fc was approxi- mately $0.3 \mathrm{mg} / \mathrm{mL}$. Even though the final yields are similar, the major difference between these two methods is the purity of the L1-Fc obtained.

This method is also useful in other cases where the Fc-fusion proteins are secreted at much higher levels. Comparison of the one-step vs. the modified-purification methods for the amino-terminal domains of human receptor protein tyrosine phosphatase beta (RPTP $\beta$ ) consisting of the fibronectin domain $(\mathrm{F})$ and the $\mathrm{S}$ region $(\mathrm{S})(10)$ and of the mouse neuron glia cell adhesion molecule (Ng-CAM)-related (Nr-

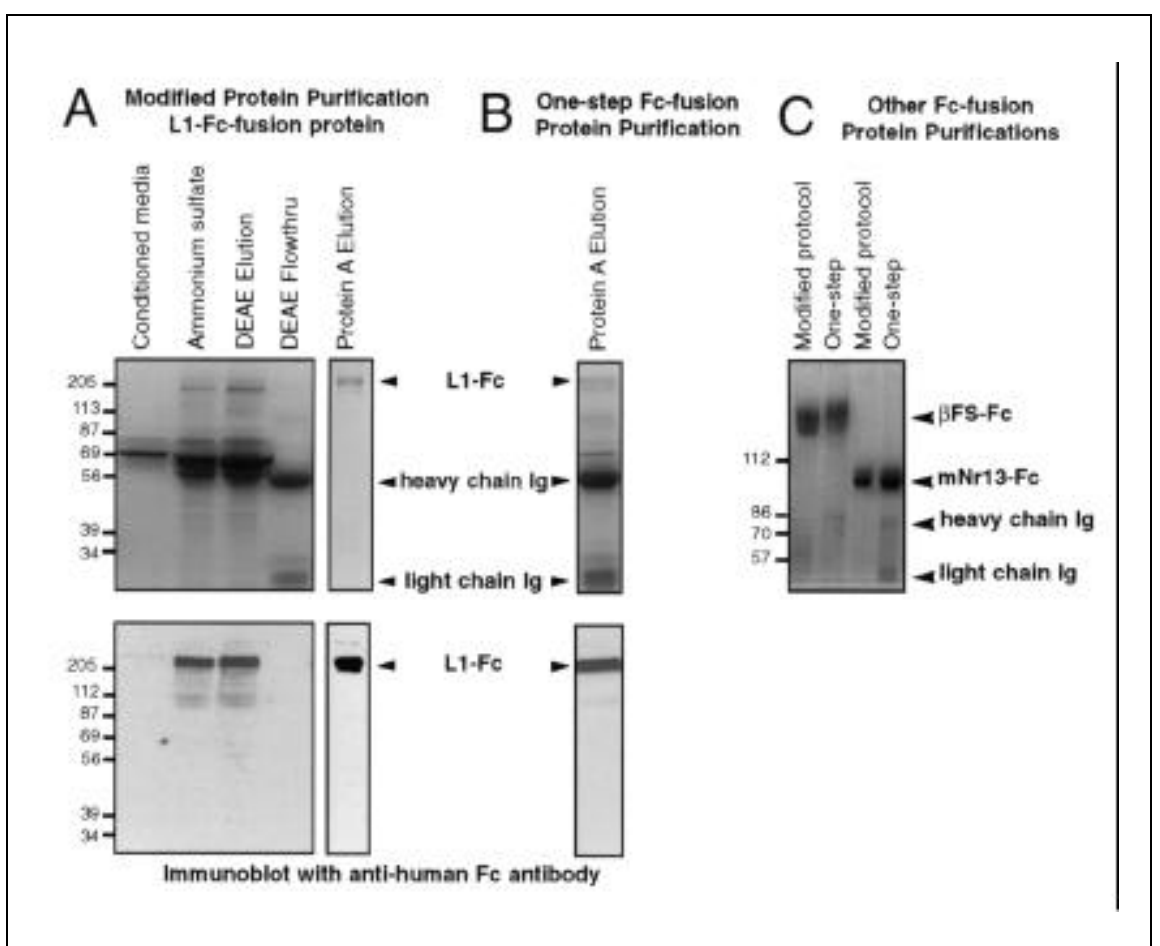

Figure 1. Purification of Fc-fusion proteins by one-step protein A-Sepharose and new modified DE52 method. (A) Sodium dodecyl sulfate polyacrylamide gel electrophoresis (SDS-PAGE) and Western blotting profiles of fractions from each step of the modified purification method. L1-Fc was purified from supernatant of $\mathrm{CHO}$ cells cultured in the presence of $2 \%-10 \% \mathrm{FCS}$ (about $0.5 \mu \mathrm{g}$ of L1-Fc/mL of supernatant) by ammonium sulfate precipitation, DE- 52 column chromatography and protein A bead column chromatography. $5-\mu \mathrm{L}$ samples of the conditioned medium and ammonium sulfate fractions and $30 \mu \mathrm{L}$ of the DEAE elution and flow-through fractions were subjected to SDS-PAGE, visualized with Coomassie Brilliant Blue (upper panels), and Western blotting (lower panels) detected with anti-human Ig antibody followed by the chemiluminescence detection. L1-Fc bound to the DE-52 column, and no L1-Fc was detected in the flow-through fraction, which contained the Ig. L1-Fc was further purified and concentrated by protein-A affinity column. The final preparation does not have any visible contaminating Ig bands. (B) SDS-PAGE and Western blotting profiles of L1-Fc purified by one-step purification method. L1-Fc was directly purified from the culture supernatant by protein-A affinity column. To compare the two procedures, equivalent fractions of the starting material were loaded in each protein A lane in Panels A and B. Note that there are major contaminating Ig bands in the one-step preparation, but the yields of L1-Fc were similar. (C) Comparison of one-step and modified purification methods for other Fc-fusion proteins. Human $\beta F S-F c$ and mouse Nr-CAM 1-3 Ig domains-Fc each were purified from supernatants of 293 cells cultured in the presence of $2 \%$ FCS (about 1-5 $\mu \mathrm{g}$ of fusion proteins $/ \mathrm{mL}$ of supernatants) by either modified or one-step purification methods and were subjected to SDS-PAGE visualized with Coomassie Brilliant Blue; equivalent fractions of the starting material were loaded for each purification method. In both cases, fractions from one-step purifications have minor contaminating Ig bands. 


\section{Benchmarks}

CAM) consisting of the first three $\mathrm{Ig}$ domains (3) shows that the modified procedure yields cleaner preparations of Fc-fusion proteins (Figure 1C). Typical yields for these $\mathrm{Fc}$-fusion proteins were approximately $1 \mathrm{mg} / \mathrm{mL}$.

In summary, we have devised a general method for purifying small or large amounts of Ig-fusion proteins that are secreted from cells grown in culture. This method has been applied to cell surface and extracellular proteins containing Ig domains and other domains, including fibronectin type III repeats and carbonic anhydrase domains $(2,3,5$, $7,10)$. It is likely that this method could be used to purify Ig-fusion proteins from endogenous Ig in products of animal culture systems such as ascites. This procedure has also been used in the purification of Ig-fusion proteins from myeloma cells that express Ig-fusion proteins (8), as we have done using chick Ng-CAM (unpublished observa- tions). Monoclonal antibody affinity purification is an alternative for removal of contaminating Ig, but appropriate antibodies must be available for each individual protein of interest. In contrast, DE-52 is commercially available and is relatively inexpensive. Alternatives to this approach include: $(i)$ use of protein-A affinity methods to pre-absorb the Ig from serum; however, this may be problematic in certain cases because of the large amounts of Ig that are present in serum and the need to maintain sterility for cell culture to produce Ig fusion protein; and (ii) use of serum-free medium that is not always optimal or possible.

Given the recent explosion in the preparation of Ig-fusion proteins for various cell-surface receptors, adhesion molecules, growth factors and orphan ligands/receptors, this method will be useful in situations where removal of contaminating Ig is important for bind- ing, detection or purification. The use of Ig-fusion proteins is likely to increase further for analytical, experimental and clinical applications, where they can function as bioactive agents to mimic or block the action of various cell surface and extracellular proteins and growth factors. It is interesting that an Fc-fusion protein with tumor necrosis factor (TNF) receptor has already been proven effective in a clinical trial (6).

\section{REFERENCES}

1.Ashkenazi, A. and S.M. Chamow. 1997. Immunoadhesions as research tools and therapeutic agents. Curr. Opin. Immunol. 9:195-200.

2.Burgoon, M.P., M. Grumet, V. Mauro, G.M. Edelman and B.A. Cunningham. 1991. Structure of the chicken neuron-glia cell adhesion molecule, Ng-CAM: origin of polypeptides and relation to Ig superfamily. J. Cell Biol. 112:1017-1029.

3.Grumet, M., V. Mauro, M.P. Burgoon, G.M. Edelman and B.A. Cunningham. 1991. 
Structure and characterization of $\mathrm{Nr}-\mathrm{CAM}$, a new member of the Ig superfamily that is closely related to Ng-CAM. J. Cell Biol. 113:1399-1412.

4.Harlow, E. and D. Lane.1988. Antibodies. A Laboratory Manual. p. 1-726. CSH Laboratory Press, Cold Spring Harbor Laboratory, NY.

5.Moos, M., R. Tacke, H. Scherer, D. Teplow, K. Fruh and M. Schachner. 1988. Neural adhesion molecule L1 as a member of the immunoglobulin superfamily with binding domains similar to fibronectin. Nature 334: 701-703.

6.Moreland, L.W., S.W. Baumgartner, M.D. Schiff, E.A. Tindall, R.M. Fleischmann, A.L. Weaver, R.E. Ettlinger, S. Cohen et al. 1997. Treatment of rheumatoid arthritis with a recombinant human tumor necrosis factor receptor (p75)-Fc fusion protein. N. Engl. J. Med. 337:141-147.

7.Peles, E., M. Nativ, P.L. Campbell, T. Sakurai, R. Martinez, S. Lev, D.O. Clary, J. Schilling et al. 1995. The carbonic anhydrase domain of receptor tyrosine phosphatase $\beta$ is a functional ligand for the axonal cell recognition molecule contactin. Cell 82:251-260.

8.Rader, C., E.T. Stoeckli, T. Osterwalder, B. Kunz and P. Sonderegger. 1993. Cell-cell adhesion by homophilic interaction of the neuronal recognition molecule axonin-1. Eur. J. Biochem 215:133-141.

9.Roonprapunt, C., D. Friedlander, A. Hooper, M. Rothman, M. Grumet and W. Young. 1997. Exogenous applied L1-Fc or laminin neutralizes the white matter inhibition of neurite outgrowth in vitro. Soc. Neurosci. Abs. 23:598

10.Sakurai, T., M. Lustig, M. Nativ, J.J. Hemperly, J. Schlessinger, E. Peles and $M$. Grumet. 1997. Induction of neurite outgrowth through neuronal cell adhesion molecules contactin and $\mathrm{Nr}-\mathrm{CAM}$ by extracellular regions of glial receptor tyrosine phosphatase $\beta$. J. Cell Biol. 136:907-918.

We thank Dr. Melitta Schachner for kindly providing $\mathrm{CHO}$ cells expressing mouse L1-Fc and Marc Lustig for technical assistance. This work was supported by a grant from NIH (Grant No. NS33921), and Acorda Therapeutics Inc. provided support to purify mouse $\mathrm{LI}$ and chick $\mathrm{Ng}-16 \mathrm{Fc}$-fusion proteins. Address correspondence to Dr. Martin Grumet, Dept. of Pharmacology, New York University Medical Center, 550 First Avenue, New York, NY 10016, USA. Internet: grumem01@mcrcr.med.nyu.edu

Received 13 February 1998; accepted 3 June 1998.

\section{Takeshi Sakurai, Chanland} Roonprapunt and Martin Grumet NYU Medical Center New York, NY, USA

\section{Inexpensive Motion Detectors for Quantifica- tion of Animal Activity}

BioTechniques 25:385-388 (September 1998)

Measurement of locomotor activity of captive animals is important in such fields as chronobiology, physiology, animal behavior and ecology. Because running wheels are convenient and can be made inexpensively, they are the most commonly used device to quantify activity, particularly in studies of rodents (2). However, wheel running is unnatural behavior, and activity measurements do not necessarily correlate with activity in large enclosures or in natural environments $(5,10)$. Tilt floors and treadles also can be used to quantify activity, but these too provide sensory feedback to the subjects and may alter behavior. It is questionable whether activity of animals in small cages is relevant to behavior in the field regardless of the device used to measure activity. It is clearly preferable to monitor behavior in the field if ecological implications are of importance; however, researchers often are limited by the objectives of the experiment or other constraints and must conduct laboratory studies. Under these circumstances, it is best to minimize error resulting from measurement methods such as running wheels. Activity measurements are expected to be more closely correlated with the behavior of free-living animals if obtained using devices that do not provide sensory feedback. For those conducting ecological research, a method of collecting data under these circumstances is desirable.

Radiotelemetry and video recording can be used to measure activity directly without affecting behavior, but each can be impractical because of time or money required. For example, radiotelemetry requires expensive equipment, and transmitters must be worn by the animals or implanted in them. Use of video cameras requires a large amount of time to evaluate and score the recorded behaviors. Vorhees et al. (9) solved this problem by using video equipment in conjunction with contrast-sensitive trackers to quantify movement over 